\title{
Experimental Investigation on Shear performance of RC beams with UHTCC layer in tension zone
}

\author{
Zhang Xiufang ${ }^{1, a}$, Liu Ruiqiang ${ }^{1, b}$ and Guo Shaopeng ${ }^{1, c}$ \\ ${ }^{1}$ Faculty of Infrastructure Engineering, Dalian University of Technology, Dalian, Liaoning, China \\ asarahdlut@126.com, bzdcgyswgx8@126.com, c1209047495@qq.com
}

\begin{abstract}
Keywords: UHTCC/RC composite beam, shear performance, interfacial debonding, crack width, cracking pattern
\end{abstract}

Abstract. Ultra-high toughness cementitious composite (UHTCC) macroscopically exhibits tensile strain hardening characteristic and excellent crack control ability due to steady development of multiple fine cracks, and therefore can be regarded as a promising repair material. Shear tests were conducted on RC beams repaired in tension zone with four different thicknesses of UHTCC layers to investigate the influence of ductile UHTCC layer on composite shear behavior of RC beam. It was found that the tested UHTCC/RC composite beams showed at least $40 \%$ higher shear capacity compared to the control RC beam and the UHTCC layer thickness has little influence on shear capacity. However, a strong influence was presented between UHTCC lay thickness and diagonal crack width. As long as the serious interface delamination developing into the supports zone was avoided, the smaller diagonal crack width can be obtained in UHTCC/RC composite beam. And importantly, the provision of the densely-spaced stirrups in the composite beam was not effective in preventing the occurrence of interface debonding between UHTCC and concrete layer.

\section{Introduction}

Ultra high toughness cementitious composites (UHTCC), which is reinforced by PVA short fiber with the volume fraction of no more than $2.0 \%$, is a high performance cementitious composite developed through the micro optimization of matrix, fiber and interfacial properties ${ }^{[1 \sim 2]}$. Generally, unlike the traditional plain concrete, UHTCC well delays brittle failure due to localization of cracks by the steady development of multiple fine cracks and therefore shows the superior tensile properties, i.e. the tensile strain hardening behavior with ultimate tensile strain up to $3 \%$ and excellent crack control ability with maximum crack widths below $100 \mu \mathrm{m}$. Because of these advantages, UHTCC is being used as a repairing material in RC structures to improve their durability and mechanical behavior ${ }^{[3 \sim 4]}$.

In recent years, a lot of experimental researches have been conducted on UHTCC/RC composite members in which a layer of concrete around the tension longitudinal steel reinforcement of members is replaced with ductile UHTCC material. Experimental observations on the bending performance of composite ECC/RC beams by Maalej et al ${ }^{[5]}$ showed that the wider cracks in the upper concrete layer were effectively suppressed by UHTCC layer and developed down into the multiple micro-cracks. Eventually, a low crack width of only $0.051 \mathrm{~mm}$ under normal service condition was obtained in the composite beam. Similar results were also reported in the study of flexural UHTCC/RC composite beam carried out by $\mathrm{Xu}$ et $\mathrm{al}^{[6-8]}$. Kim et al. ${ }^{[9]}$ investigated the composite shear behavior of $\mathrm{RC}$ beams repaired using twice the cover thickness DFRCC on the tensile face of RC specimens. They concluded that there was no improvement of shear strength in 
the composite beams when compared to the RC reference beams because of the serious interface debonding between concrete and UHTCC layer. However, the test results of Zhang et al ${ }^{[10]}$. showed a higher shear strength in SHCC (Strain Hardening Cement-based Composite)/RC composite beam than that in RC beam. Obviously, more works are still desired to further understand the shear performance of UHTCC/RC composite beam.

In this paper, shear tests are conducted on beam specimens where the different thickness of concrete around the longitudinal steel reinforcement at the tensile side are replaced by the tensile ductile UHTCC, with the main purpose for investigating the influence of UHTCC layer thickness on shear performance of UHTCC/RC composite beams.

\section{Experimental program}

\section{Materials}

The UHTCC material used in the test was composed of PVA fibers and cementitious matrix. A $12 \mathrm{~mm}$ long PVA fiber with a diameter of $0.04 \mathrm{~mm}$ was utilized and its tensile elastic modulus and tensile strength were $40 \mathrm{GPa}$ and $1600 \mathrm{MPa}$, respectively. The dry components of cementitious matrix contain Ordinary Portland Cement, fine sand, fly ash and mineral admixture. UHTCC composite material was produced in the regular mixer. Commercial concrete with the target compressive strength of 50MPa was provided with the mix proportion of cement: river sand: gravel: water $=360:$ 685: 1050: 185. Two ribbed steel bars with a diameter of 20mm were used as tensile longitudinal reinforcement and plain steel bars with diameters of $8 \mathrm{~mm}$ and $6.5 \mathrm{~mm}$ were used as shear stirrups and compression construction reinforcement, respectively. The other reinforcement strengths, compression strengths of UHTCC and concrete were given in Table 1.

Table 1 Details of tested beams

\begin{tabular}{lcccccccc}
\hline Specimens & $\begin{array}{c}\text { UHTCC } \\
\text { thickness }[\mathrm{mm}]\end{array}$ & $f_{\mathrm{cu}}[\mathrm{MPa}]$ & $\rho_{\mathrm{v}}[\%]$ & $f_{\mathrm{yv}}[\mathrm{MPa}]$ & $f_{\mathrm{uv}}[\mathrm{MPa}]$ & $\rho_{\mathrm{l}}[\%]$ & $f_{\mathrm{yl}}[\mathrm{MPa}]$ & $f_{\mathrm{ul}}[\mathrm{MPa}]$ \\
\hline U0S150 & 0 & 52.07 & & & & & & \\
U40S150 & 40 & 55.30 & 0.314 & 360 & 491 & 2.804 & 675 & 796 \\
U60S150 & 60 & 55.90 & & & & & & \\
U80S150 & 80 & 53.81 & & & & & \\
\hline
\end{tabular}
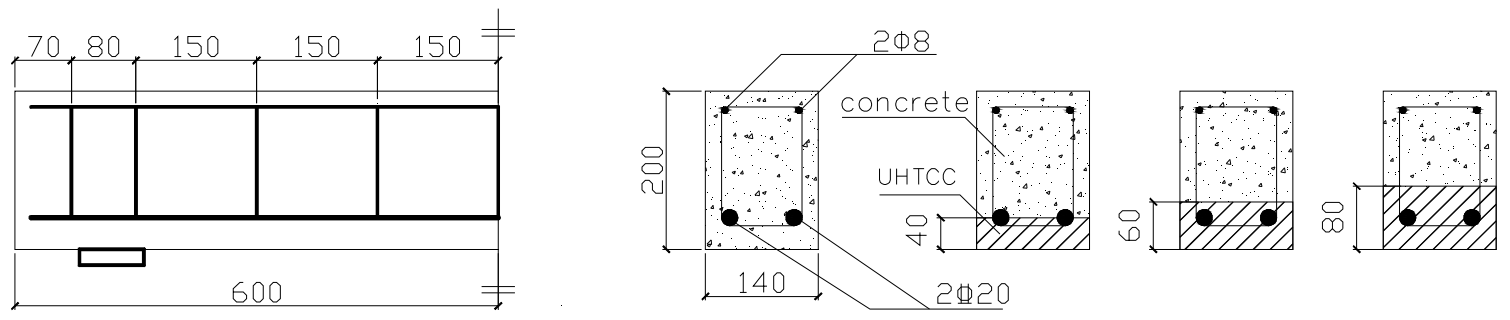

Fig. 1 Size and reinforcement details of tested beams [unit: $\mathrm{mm}$ ]

\section{Beams fabrication}

A total of 4 beams with web stirrups were prepared in this test, including one RC contrast beam and three UHTCC/RC composite beams. The geometrical size of the tested beam was $140 \mathrm{~mm} \times 200$ $\mathrm{mm} \times 1200 \mathrm{~mm}$ (width $\times$ height $\times$ length). The cover thickness was $40 \mathrm{~mm}$, corresponding to a shear span ratio of 3 . The main variable in this test was UHTCC layer thickness, i.e. $0 \mathrm{~mm}, 40 \mathrm{~mm}, 60 \mathrm{~mm}$ 
and $80 \mathrm{~mm}$ respectively. The spacing of stirrups was set $150 \mathrm{~mm}$, which produces a shear stirrup ratio larger than the minimum shear stirrup ratio. Fig. 1 plotted the details of the tested beams.

The wood mold was utilized to finish the casting of all the tested beams where the concrete layer were firstly cast and vibrated and then the UHTCC layer was subsequently placed before the initial set of concrete. The beams were covered by the plastic membrane after casting to reduce the loss of water. All beam specimens were placed outside for 28 days air curing and were water-sprayed twice every day.

\section{Shear test setup and measurements}

All beams were loaded under concentrated load at midspan through the $10000 \mathrm{kN}$ electronic universal testing machine. A load sensor with the maximum capacity of $500 \mathrm{kN}$ was connected to obtain more precise load. Three LVDTs were fixed at the mid-span and the supports to measure deflection. A plate with a width of $80 \mathrm{~mm}$ was placed at the loading point and the support point in order to avoid the local compression failure. The load was applied gradually by using a first load-control loading mode with load level of $5 \mathrm{kN}$ and then displacement-control loading mode after the reach of $60 \%$ predicted ultimate bearing capacity until the load at the descending stage dropped to $70 \%$ peak load.

\section{Test results and discussions}

\section{Failure mode}

There were two typical failure modes: shear compression failure (SC) in U0S150, U60S150 and U80S150 specimens and shear compression -interface debonding failure (S-D) in beam U40S150, as shown in Table 2. For the shear compression failure, the beams eventually failed due to crush of concrete in the compression zone. Although the interface delamination between concrete and UHTCC layer also happened in the beams U60S150 and U80S150, the interface cracks did not extend into the supports and their development stopped before final shear failure. The wide main diagonal crack only appeared in the UHTCC layer not in the concrete layer. For shear compression - interface debonding failure, the interface delamination took place continuously during the whole loading process and each peeling along the interface further accelerated the extension of the critical diagonal cracks. The beam eventually failed when the interface cracks extended into the support position and the compressive concrete was crushed at the same time.

Fig. 2 presented the photos of crack development in all tested specimens observed by naked eye after unloading. It was noticed that, although some of fine cracks appeared in UHTCC layer of the composite beam have been closed after unloading, there was still more diagonal cracks in UHTCC layer when compared to RC beams. And, the number of cracks in composite beams increased with the increase in the thickness of UHTCC layer. Moreover, the interface delamination repeatedly happened and alternately developed in the left and right shear span zone during the whole loading. After each debonding, a great number of multiple fine cracks gradually appeared in UHTCC layer around the tip of the interface crack, which delayed the occurrence of the interface debonding or even avoided the debonding failure. From Fig. 2, it seemed that the 1.5 times cover thickness $(60 \mathrm{~mm})$ of UHTCC layer is enough to avoid the debonding failure occurred in the specimen U40S150 where a cover thickness of concrete layer was replaced with UHTCC.

In the U60S150 and U80S150 composite beams, because UHTCC could deform compatibly with steel reinforcement, no horizontal splitting crack along the tensile longitudinal reinforcements occurred. 

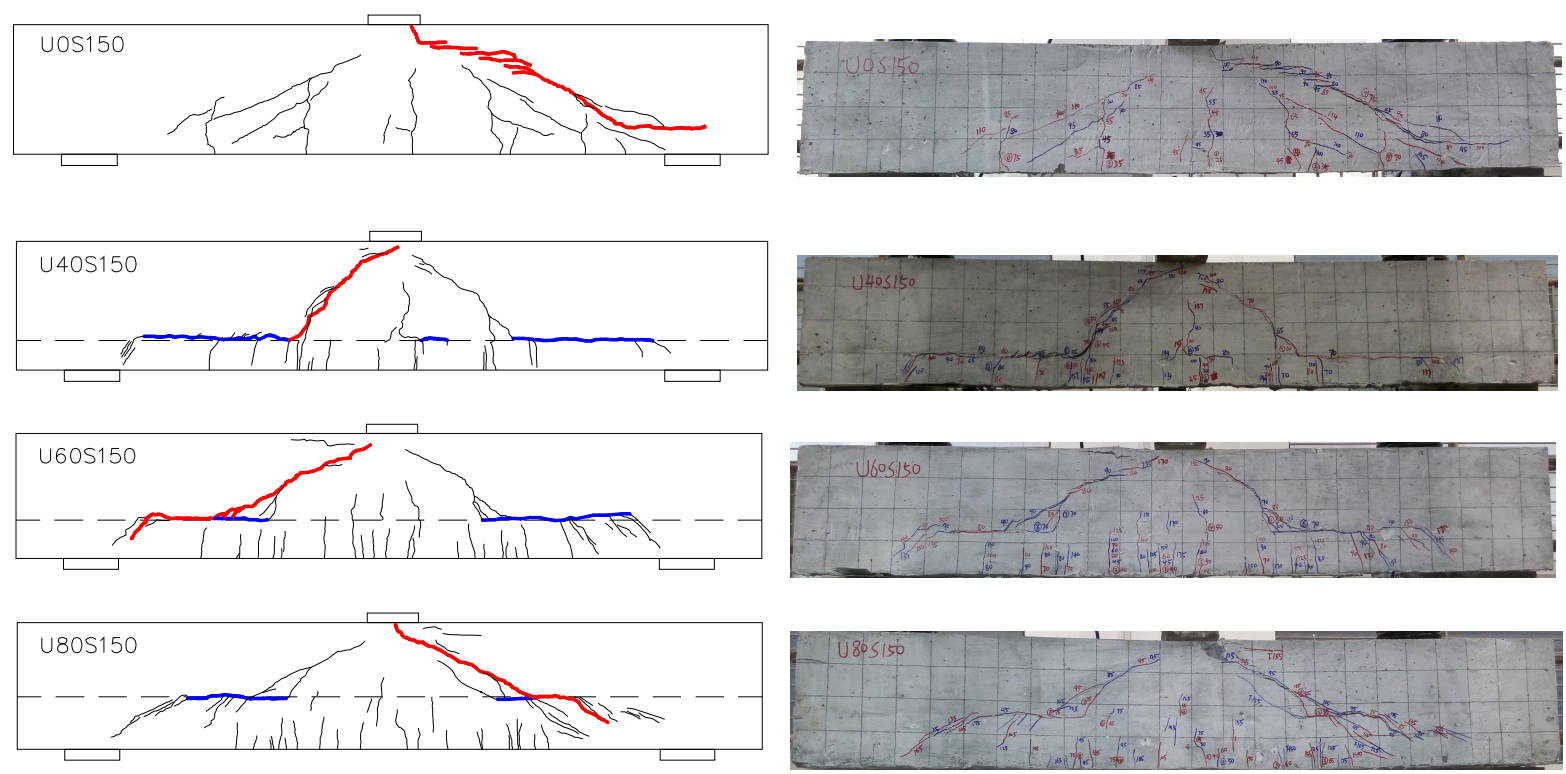

Fig. 2 Cracking behavior of specimens after unloading

Table 2 Tested loads and failure mode

\begin{tabular}{ccccccc}
\hline Specimens & $P_{\mathrm{cr}}[\mathrm{kN}]$ & $P_{\mathrm{S}}[\mathrm{kN}]$ & $P_{\mathrm{u}}[\mathrm{kN}]$ & $\delta_{\mathrm{u}}[\mathrm{mm}]$ & $P_{\mathrm{u}} / P_{\mathrm{cr}}$ & Failure mode \\
\hline U0S150 & 55 & - & 114 & 5.35 & 2.07 & $\mathrm{SC}$ \\
U40S150 & 45 & 55 & 158 & 4.24 & 3.51 & $\mathrm{~S}-\mathrm{D}$ \\
U60S150 & 60 & 70 & 176 & 5.11 & 2.93 & $\mathrm{SC}$ \\
U80S150 & 75 & 75 & 174 & 4.21 & 2.32 & $\mathrm{SC}$ \\
\hline
\end{tabular}

Notes: $P_{\mathrm{cr}}$ - the shear cracking load; $P_{\mathrm{cs}}$ the initial interfacial debonding load; $P_{\mathrm{u}}$ - peak load; $\delta_{\mathrm{u}}$ - peak deflection.

\section{Load}

The shear cracking load $P_{\mathrm{cr}}$, initial interfacial debonding load $P_{\mathrm{s}}$ and peak load $P_{\mathrm{u}}$ of the tested beams were summarized in Table 2. As seen in Table 2, compared to RC control beam, a greatly improved shear capacity was obtained in the UHTCC/RC composite beams and the improvement increased with the increase in the thickness of UHTCC layer. This was mainly because the bridging effect of UHTCC layer can well transfer tensile stress after the concrete cracking in the tension zone, which provided much shear resistance. Table 2 also presented that, the interface debonding crack appeared in the UHTCC/RC composite beams soon after the shear cracking and the composite beams with thick UHTCC layer showed slightly high initial interfacial debonding load.

In Table 2, the ratios of ultimate shear capacity to shear cracking load were listed for all tested specimens, too. UHTCC/RC composite beams had a minimum ratio of 2.32 which was still greater than 2.07 in RC beam, indicating that the replacement of brittle concrete with the ductile UHTCC layer can enhance shear ductility before peak failure.

\section{Load-deflection behavior}

The load-deflection curves of all tested specimens were shown in Fig. 3. For RC beam U0S150 without UHTCC, the load linearly increased at the initial loading stage as the deflection increased. Once the shear cracking initiated, the specimen began to behave nonlinearly and the stiffness started to degrade. The shear compression failure occurred at the peak load of $114 \mathrm{kN}$ and the corresponding peak deflection was $5.35 \mathrm{~mm}$. Afterward, the load slowly dropped. At a load of about $90 \mathrm{kN}$, a steady platform appeared at the descending stage and the deflection may be imposed up to 
$12.69 \mathrm{~mm}$, showing good deformation ductility after peak failure. This was possibly because of the great restriction action provided by a higher stirrup ratio that is about 1.4 times the minimum stirrup ratio.

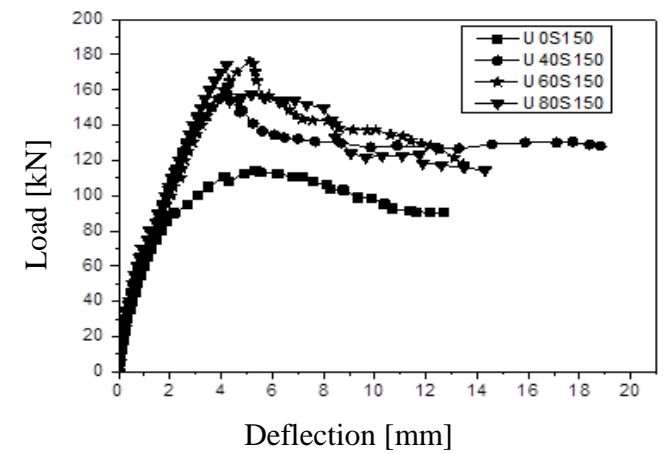

Fig. 3 Load deflection curves of tested beams

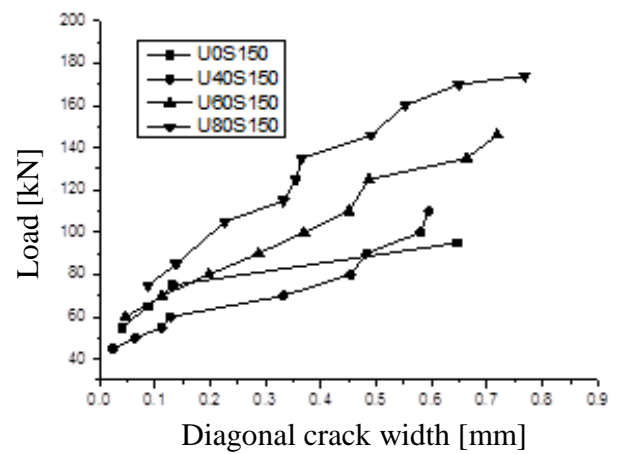

Fig. 4 Diagonal crack widths with loading

For composite beams, similar load-deflection behavior to U0S150 specimen was observed before the appearance of shear diagonal crack. Although the elastic modulus of UHTCC was lower than that of concrete in the present test, the speed of stiffness degradation after shear cracking was significantly reduced in the composite beams. This can be not only because of the multiple fine cracks in bottom UHTCC layer, but also because of the narrow diagonal crack in upper concrete layer due to the restriction action by UHTCC layer. Therefore, while further increasing load after initial shear cracking, three composite beams were noticed to have higher deflection stiffness than $\mathrm{RC}$ control beam and, meanwhile, presented an approximately linear increase with the deflection until the peak load was reached. Additionally, it was also noticed that the UHTCC layer thickness had negligible effect on the deflection stiffness. After the peak load, the sharp load-drop was observed initially in the composite beams due to the debonding delamination along the interface between concrete and UHTCC layer. About after $150 \mathrm{kN}$, load started to slowly reduce up to about $130 \mathrm{kN}$ at which almost horizontal load-deflection curves were recorded.

From Fig. 3, for the composite beams that contained 1.4 times minimum stirrup ratio, load up-down fluctuating on the load-deflection curves were not seen prior to peak load in respective of UHTCC layer thickness, which was different from the load-deflection behavior in composite beam without shear stirrups in which many load fluctuations occurred ${ }^{[9,11]}$.

\section{Crack width}

The variation of loads with the increase of diagonal crack width was shown in Fig. 4 for all specimens. In Fig. 4, the diagonal crack width was limited within 0.8mm. At the same load level, the diagonal crack width in the composite beam U40S150 was biggest among all specimens. It should be noted that, for the U40S150 that has a cover thickness of UHTCC layer, the interface between UHTCC and concrete layer is just at the same height level as the interface between steel bar and concrete, which led to the serious interface debonding and the large deflection. When the UHTCC layer thickness was increased by 1.5 times even double cover thickness, i.e. the beams U60S150 and U80S150, the interface debonding was alleviated so that the diagonal crack with the smaller width developed at the same load level compared to the control RC beam. Therefore, it can be predicted that, if the interface debonding was fully eliminated in the UHTCC/RC composite beam, the ability of UHTCC layer to limit opening of diagonal crack in the RC layer will be more significant. Additionally, it can be also seen from Fig. 4 that an increase in the UHTCC layer thickness would result in a decrease in the diagonal crack width. 


\section{Conclusions}

In this paper, the shear tests of UHTCC / RC composite beams with web reinforcement were carried out, in which the four different thicknesses were designed for UHTCC layer. Results showed that, three UHTCC/RC composite beams obtained greatly improved shear capacity compared to the control RC beam. UHTCC layer thickness had little influence on shear capacity when it is larger than cover thickness of RC beam. While for diagonal crack width, the UHTCC thickness has significant influence. The composite beam with thicker UHTCC layer showed smaller crack width. Generally speaking, 1.5 times cover thickness (about $60 \mathrm{~mm}$ in the present test) is suggested for the composite beam to obtain a superior crack control to RC reference beam. It was also concluded that the interface debonding between UHTCC and concrete layer happened even if the densely-spaced stirrups were provided in the composite beam. Therefore, to only increase amount of stirrups was not effective method to prevent the interface debonding between UHTCC and concrete layer.

\section{Acknowledgements}

This work was financially supported by National Natural Science Foundation of China (51478078) and the Fundamental Research Funds for the Central Universities (DUT15LK39).

\section{References}

[1] V.C. Li: Journal of Structural Mechanics and Earthquake Engineering Vol. 10 (1993), p. 37

[2] ShiLang Xu, HeDong Li: China Civil Engineering Journal Vol. 41 (2008), p. 45 (in Chinese)

[3] V.C. Li: International Journal for Restoration of Building and Monuments Vol. 10 (2004), p. 163

[4] Y.M. Lim, V.C. Li: Cement and Concrete composites Vol. 19 (1997), p. 373

[5] M. Maalej, V.C. Li: ACI Structural Journal Vol, 92 (1995), p. 167

[6] N. W, S.L. Xu: Journal of Central South University Vol. 18 (2011), p. 932

[7] X.F. Zhang, S.L. Xu and K.Y.L Christopher: Advances in Structural Engineering Vol. 15 (2012), p. 319

[8] S.L. Xu, L.J. Hou and X.F. Zhang: Engineering Structures Vol. 39 (2012), p: 176

[9] J.H.J. Kim, M.L. Yun, P.J. Won, et al: Engineering Structures Vol. 29 (2007), p. 121

[10]Y. Zhang, S. Bai, Q. Zhang, et al: Construction and Building Materials Vol. 78 (2015), p. 470

[11]LiJun Hou, Da Chen, JinYong Sun, et al: Journal of Hydraulic Engineering Vol. 45 (2014), p. 100 (in Chinese) 